\title{
A comprehensive analysis of differentially expressed genes and pathways in abdominal aortic aneurysm
}

\author{
KAI YUAN, WEI LIANG and JIWEI ZHANG
}

\begin{abstract}
Department of Vascular Surgery, Renji Hospital of Shanghai Jiao Tong University School of Medicine, Shanghai 200127, P.R. China
\end{abstract}

Received May 29, 2014; Accepted March 3, 2015

DOI: $10.3892 / \mathrm{mmr} .2015 .3709$

\begin{abstract}
The current study aimed to investigate the molecular mechanism underlying abdominal aortic aneurysm (AAA) via various bioinformatics techniques. Gene expression profiling analysis of differentially expressed genes (DEGs) between AAA samples and normal controls was conducted. The Database for Annotation, Visualization and Integrated Discovery tool was utilized to perform Gene ontology (GO) and Kyoto Encyclopedia of Genes and Genomes analyses for DEGs and clusters from the protein-protein interaction (PPI) network, which was constructed using the Search Tool for the Retrieval of Interacting Genes. In addition, important transcription factors (TFs) that regulated DEGs were investigated. A total of 346 DEGs were identified between AAA samples and healthy controls. Additionally, four clusters were identified from the PPI network. Cluster 1 was associated with sensory perception of smell and the olfactory transduction subpathway. The most significant $\mathrm{GO}$ function terms for cluster 2 and 3 were response to virus and defense response, respectively. Cluster 4 was associated with mitochondria-associated functions and the oxidative phosphorylation subpathway. Early growth response-1 (EGR-1), Myc, activating transcription factor 5 (ATF5) and specificity protein (SP) 1:SP3 were identified to be critical TFs in this disease. The present study suggested that the olfactory transduction subpathway, mitochondria and oxidative phosphorylation pathways were involved in AAA, and TFs, such as EGR-1, Myc, ATF5 and SP1:SP3, may be potential candidate molecular targets for this disease.
\end{abstract}

\section{Introduction}

Abdominal aortic aneurysm (AAA), the most common form of aortic aneurysm, refers to a localized dilatation of the abdom-

Correspondence to: Dr Jiwei Zhang, Department of Vascular Surgery, Renji Hospital of Shanghai Jiao Tong University School of Medicine, 160 Pujian Road, Shanghai 200127, P.R. China

E-mail: zhangjiwei001@sina.com

Key words: abdominal aortic aneurysm, olfactory receptor, mitochondria, oxidative phosphorylation inal aorta exceeding the normal aortic diameter by $>50 \%$ (1). The most severe complication of AAA is AAA rupture, which is the tenth primary cause of mortality for American Caucasian males between 65-74 years old (2). As AAA rupture is fatal within minutes, in the majority of cases, the patients do not reach hospital in time to receive treatment. Therefore, the mortality rate of AAA rupture is $\sim 90 \%$ (3).

Thus, there is an urgent requirement for the development of effective therapies for AAA, and elucidating the etiology of AAA is important in this development. Chronic tobacco smoking has been identified as the most important risk factor for AAA $(4,5)$. In addition to smoking, inherited susceptibility to AAA has also been identified as a critical causative factor accounting for this disease (6). The molecular mechanism of AAA has been widely investigated. In particular, protease inhibitors, such as metalloproteinase inhibitor-2 and plasminogen activator inhibitor-1 have been reported to be involved in the development of AAA from original atherosclerotic plaques (7). $\beta$-arrestin- 2 , a scaffolding protein, has been suggested to promote AAA formation induced by angiotensin II in mice in a previous study (8). Additional studies suggested that Sortilin-1 and microRNA-29b were also involved in the pathogenesis of AAA $(9,10)$.

Thus, previous studies have made progress in understanding the pathogenesis of AAA; however, the underlying mechanisms of AAA remain to be fully elucidated. The current study aimed to clarify the molecular mechanism of AAA using bioinformatics techniques. Differentially expressed genes (DEGs) were identified through analyzing the whole genome gene expression profiles of 14 AAA samples. Gene ontology (GO) and Kyoto Encyclopedia of Genes and Genomes (KEGG) analyses were conducted for DEGs, and a protein-protein interaction (PPI) network was constructed followed by analysis of clusters from the PPI network. Additionally, important transcription factors (TFs) that regulated DEGs were investigated. The observations of the current study may provide novel insights into the pathogenesis of this disease and aid in the development of future therapeutic approaches to treat AAA.

\section{Materials and methods}

Microarray data. In order to investigate the molecular mechanism of AAA, the gene expression profile of GSE47472 was obtained from the National Center of Biotechnology 
Information (NCBI) Gene Expression Omnibus (GEO) database (http://www.ncbi.nlm.nih.gov/geo/). This was used with the Illumina HumanHT-12 V4.0 Expression BeadChip kit (Illumina, Inc., San Diego, CA, USA), which had a total of 22 gene chips, consisting of 14 AAA samples and 8 control aortic samples.

Data preprocessing and DEG analysis. The probe-level data in CEL files was converted into expression measures using the Log2 transformation following data preprocessing with the median method using the preprocessCore package (11). In total, there were 39,426 probes for 17,393 genes. When there were multiple probes corresponding to one given gene, expression values of these probes were averaged.

DEGs between AAA specimens and controls were identified using the multiple linear regression package limma (12) in Bioconductor (13), followed by multiple testing correction using the Bayesian inference method. $\log \mathrm{FCl}>1$ and false discovery rate $(\mathrm{FDR})<0.05$ were set as the strict cutoffs.

$G O$ and KEGG enrichment analysis for DEGs. For functional annotation of DEGs, the Database for Annotation, Visualization and Integrated Discovery (DAVID) (14) was utilized to perform GO (15) and KEGG (16) analyses for the identified DEGs. $\mathrm{P}<0.05$ was set as the strict threshold.

PPI network construction. In order to investigate the interactions among proteins encoded by DEGs and their associations with diseases, the Search Tool for the Retrieval of Interacting Genes online tool (17) was applied to construct a PPI network, which was visualized using Cytoscape 3.0.0 software (http://www.cytoscape.org/) (18). Hub proteins were identified by analyzing the node degree. The proteins in the network were defined as the 'nodes' and a pair of interacted proteins were linked by an edge. The 'degree' of a node represents the number of interactions that node has. The nodes with high degrees were considered as hub nodes.

Analysis of network clustering. Network clustering was performed using ClusterONE (19) in Cytoscape software with $\mathrm{P}<0.01$ as a cutoff. The DAVID online tool was applied to perform $\mathrm{GO}$ and KEGG pathway analysis for network clusters with $\mathrm{P}<0.05$ set as the threshold.

Detection of upstream regulatory elements. To investigate TFs that modulated the up- and downregulated DEGs, the upstream regulatory elements for TFs, which were also termed transcription factor binding sites (TFBS) were identified using the Whole-Genome rVISTA online tool (http:// genome.lbl.gov/cgi-bin/WGRVistaInputCommon.pl). The length parameter for the gene promoter region was set at 1,000 base pairs upstream of the transcriptional start site with $\mathrm{P}<0.0001$ as the strict cutoff.

\section{Results}

DEG screening. In total, 346 DEGs were selected between 14 AAA and 8 control samples. Among these DEGs, $61 \%$ (212) were upregulated, while $39 \%$ (134) were downregulated.
GO and KEGG enrichment analysis. GO functional analysis was performed for up- and downregulated DEGs. As presented in Table I, up- and downregulated DEGs were enriched in 6 and 4 GO function terms, respectively. Cellular sodium ion homeostasis and regulation of RNA metabolic process were identified to be the most significant GO function terms for the up- and downregulated DEGs, respectively. Using $\mathrm{P}<0.05$ as the threshold for significance, no DEG was observed to be significantly enriched in any sub-pathway of KEGG.

PPI network construction. As demonstrated in Fig 1, 88 interactions were identified among proteins in the PPI network. Proteins with a degree $>4$ consisted of tyrosine-protein kinase (HCK), ribosomal protein L5 (RPL5), olfactory receptor 52E4 (OR52E4), TYRO protein tyrosine kinase-binding protein (TYROBP) and nuclear receptor co-repressor 1 (NCOR1).

Network cluster analysis. Four network clusters were identified from the PPI network (Fig. 2). Among the four clusters, cluster 1 included OR52E4, and cluster 3 included HCK and TYROBP. The results of the GO enrichment analysis for the 4 clusters are presented in Table II. Cluster 1 was identified to be most significantly enriched in the plasma membrane and sensory perception of smell. A number of olfactory receptor genes were included in cluster 1. The most significant GO terms for cluster 2 and 3 were response to virus and defense response, respectively. Interferon-induced GTP-binding protein (MX1), interferon- $\alpha / \beta$ receptor (IFNAR) and interferon-stimulated gene $20 \mathrm{kDa}$ protein (ISG20) were enriched in cluster 2. In addition, cluster 4 was enriched in mitochondria-associated functions. As presented in Table III, for cluster 1, the olfactory transduction subpathway was the most significantly enriched KEGG subpathway. DEGs including NADH dehydrogenase (ubiquinone) iron-sulfur protein 8 (NDUFS8) and cytochrome c1 (CYC1) in cluster 4 were observed to be enriched in the oxidative phosphorylation subpathway.

Identification of TFBS and TFs. For the upregulated DEGs, the important TFs identified included early growth response protein 1 (EGR-1) and Myc. In the downregulated DEGs however, activating transcription factor 5 (ATF5), specificity protein (SP)1:SP3, E2F transcription factor 4 (E2F4) and TFII-I were the critical TFs identified.

\section{Discussion}

In the current study, a total of 212 upregulated DEGs and 134 downregulated DEGs were identified between AAA samples and control samples. HCK, OR52E4 and TYROBP were identified as hub nodes in the PPI network. Four clusters from the PPI network were validated in terms of GO functions and KEGG pathways individually. In addition, important TFs were identified for up- and downregulated DEGs.

Of the four clusters from the PPI network, cluster 1 was identified to be enriched in sensory perception of smell and the olfactory transduction subpathway. Consistently, OR52E4, which was part of cluster 1 , is a member of the family of olfactory receptor proteins (20). It has been reported that tobacco exposure is able to impair olfactory function in a dose-dependent manner (21), thus given that tobacco smoking is an important 
Table I. GO enrichment analysis of DEGs.

A, Upregulated genes

\begin{tabular}{|c|c|c|c|c|}
\hline ID & Name & Gene symbol & P-value & FDR \\
\hline GO:0006883 & $\begin{array}{l}\text { Cellular sodium } \\
\text { ion homeostasis }\end{array}$ & C7, NEDD4L & 0.046429183 & 52.31338009 \\
\hline GO:0003924 & GTPase activity & $\begin{array}{l}\text { SEPT5, GBP5, RAB 11B, } \\
\text { ERAS, MX1, GNG5 }\end{array}$ & 0.044676591 & 45.15145139 \\
\hline GO:0005886 & Plasma membrane & $\begin{array}{l}\text { TGOLN2, SEPT5, OR2J2, } \\
\text { PCDHGA5, LGR5, TAAR9, } \\
\text { OR9A4, S1PR1, DYNLL1, } \\
\text { RAET1G, CEACAM6, SV2B, } \\
\text { ERAS, GNG4, SV2C, GNG5, } \\
\text { HTR1F, GJD4, ZP1, GBP5, } \\
\text { PCDHB5, CACNG8, PIK3C2A, } \\
\text { SLC34A1, MPP5, MRGPRF, } \\
\text { IFNAR1, SLC26A3, GRASP, } \\
\text { TM4SF5, C7, GPRC5D, OR1L8, } \\
\text { OR2T3, ABI1, CDH8, GORASP1, } \\
\text { RAB11B, KCNE1, SERPINC1, } \\
\text { PCSK9, OR2T8, SPRN, IL2RB, } \\
\text { DLGAP2, TMEM47, OR51A2, } \\
\text { OR8B12, EMR3 }\end{array}$ & 0.007482427 & 9.0256518 \\
\hline GO:0016023 & $\begin{array}{l}\text { Cytoplasmic membrane } \\
\text { bounded vesicle }\end{array}$ & $\begin{array}{l}\text { SEPT5, TGOLN2, ANGPTL6, } \\
\text { CACNG8, PIK3C2A, DLD, } \\
\text { RAB11B, SV2B, VGF, SV2C, } \\
\text { ARHGDIB }\end{array}$ & 0.032382066 & 33.93883034 \\
\hline GO:0030136 & Clathrin-coated vesicle & $\begin{array}{l}\text { SEPT5, TGOLN2, PIK3C2A, } \\
\text { SV2B, SV2C }\end{array}$ & 0.034758195 & 35.95313043 \\
\hline GO:0031988 & Membrane bounded vesicle & $\begin{array}{l}\text { SEPT5, TGOLN2, ANGPTL6, } \\
\text { CACNG8, PIK3C2A, DLD, } \\
\text { RAB11B, SV2B, VGF, } \\
\text { SV2C, ARHGDIB }\end{array}$ & 0.039021284 & 39.42595138 \\
\hline
\end{tabular}

B, Downregulated genes

\begin{tabular}{|c|c|c|c|c|}
\hline ID & Name & Gene symbol & P-value & FDR \\
\hline GO:0051252 & $\begin{array}{l}\text { Regulation of RNA } \\
\text { metabolic process }\end{array}$ & $\begin{array}{l}\text { ZFP36, ZNF584, HSFX2, } \\
\text { ETV7, HOXA13, RFX7, } \\
\text { SIX3, ZNF230, PA2G4, } \\
\text { FOXF1, NR2F6, HOXA10, } \\
\text { ZNF462, PER3, CARM1, } \\
\text { TCF3, NCOR1, ZNF257 }\end{array}$ & 0.046908154 & 52.01470738 \\
\hline GO:0006350 & Transcription & $\begin{array}{l}\text { ZNF584, HSFX2, ETV7, } \\
\text { SNAPC2, HOXA13, ZNF507, } \\
\text { PPP1R10, ZNF230, PA2G4, } \\
\text { NCOA5, FOXF1, NR2F6, } \\
\text { HOXA10, ZNF462, PER3, } \\
\text { CARM1, TCF3, ZNF575, } \\
\text { NCOR1, ZNF257 }\end{array}$ & 0.049224445 & 53.76642617 \\
\hline GO:0043565 & $\begin{array}{l}\text { Sequence-specific } \\
\text { DNA binding }\end{array}$ & $\begin{array}{l}\text { HSFX2, ETV7, HOXA13, } \\
\text { FOXF1, SIX3, HOXA10, } \\
\text { NR2F6, TCF3, NCOR1 }\end{array}$ & 0.035160922 & 37.25923349 \\
\hline GO:0003677 & DNA binding & $\begin{array}{l}\text { H1F0, ZFP36, ZNF584, } \\
\text { HSFX2, ETV7, SNAPC2, } \\
\text { HOXA13, ZNF507, RFX7, }\end{array}$ & 0.046429791 & 46.16041287 \\
\hline
\end{tabular}


Table I. Continued.

\begin{tabular}{lll}
\hline ID & \multicolumn{1}{c}{ Gene symbol } & P-value \\
\hline & SIX3, PPP1R10, ZNF230, \\
& XPA, PA2G4, FOXF1, NR2F6, \\
& HOXA10, ZNF462, TCF3, \\
& ZNF575, NCOR1, ZNF257 \\
\hline
\end{tabular}

GO, Gene ontology; DEG, differentially expressed genes; FDR, false discovery rate.

Table II. GO enrichment analysis for four clusters.

\begin{tabular}{|c|c|c|c|c|}
\hline \multicolumn{5}{|l|}{ A, Cluster 1} \\
\hline ID & Name & Gene symbol & P-value & FDR \\
\hline GO:0005886 & Plasma membrane & $\begin{array}{l}\text { OR9A4, OR1L8, OR8B12, } \\
\text { OR52E4, OR4C46 }\end{array}$ & $2.91 \times 10^{-2}$ & 10.65718378 \\
\hline GO:0007608 & $\begin{array}{l}\text { Sensory perception } \\
\text { of smell }\end{array}$ & $\begin{array}{l}\text { OR9A4, OR1L8, OR8B12, } \\
\text { OR52E4, OR4C46 }\end{array}$ & $4.95 \times 10^{-6}$ & 0.00285105 \\
\hline GO:0007606 & $\begin{array}{l}\text { Sensory perception of } \\
\text { chemical stimulus }\end{array}$ & $\begin{array}{l}\text { OR9A4, OR1L8, OR8B12, } \\
\text { OR52E4, OR4C46 }\end{array}$ & $7.48 \times 10^{-6}$ & 0.004306871 \\
\hline GO:0007600 & Sensory perception & $\begin{array}{l}\text { OR9A4, OR1L8, OR8B12, } \\
\text { OR52E4, OR4C46 }\end{array}$ & $6.08 \times 10^{-5}$ & 0.034971424 \\
\hline GO:0050890 & Cognition & $\begin{array}{l}\text { OR9A4, OR1L8, OR8B12, } \\
\text { OR52E4, OR4C46 }\end{array}$ & $9.59 \times 10^{-5}$ & 0.055165167 \\
\hline GO:0007186 & $\begin{array}{l}\text { G-protein coupled } \\
\text { receptor protein } \\
\text { signaling pathway }\end{array}$ & $\begin{array}{l}\text { OR9A4, OR1L8, OR8B12, } \\
\text { OR52E4, OR4C46 }\end{array}$ & $2.21 \times 10^{-4}$ & 0.126911001 \\
\hline GO:0050877 & Neurological system process & $\begin{array}{l}\text { OR9A4, OR1L8, OR8B12, } \\
\text { OR52E4, OR4C46 }\end{array}$ & $2.96 \times 10^{-4}$ & 0.170141842 \\
\hline GO:0007166 & $\begin{array}{l}\text { Cell surface receptor linked } \\
\text { signal transduction }\end{array}$ & $\begin{array}{l}\text { OR9A4, OR1L8, OR8B12, } \\
\text { OR52E4, OR4C46 }\end{array}$ & 0.001573052 & 0.901913236 \\
\hline GO:0004984 & Olfactory receptor activity & $\begin{array}{l}\text { OR9A4, OR1L8, OR8B12, } \\
\text { OR52E4, OR4C46 }\end{array}$ & $1.20 \times 10^{-6}$ & $1.20 \times 10^{-4}$ \\
\hline
\end{tabular}

B, Cluster 2

\begin{tabular}{lllll}
\hline ID & Name & Gene symbol & P-value & FDR \\
\hline GO:0009615 & Response to virus & MX1, IFNAR1, ISG20 & $3.82 \times 10^{-4}$ & 0.354852933 \\
\hline
\end{tabular}

C, Cluster 3

\begin{tabular}{|c|c|c|c|c|}
\hline ID & Name & Gene symbol & P-value & FDR \\
\hline GO:0006952 & Defense response & $\begin{array}{l}\text { S100A8, NCF1, HCK, } \\
\text { TYROBP }\end{array}$ & $8.73 \times 10^{-4}$ & 0.795749167 \\
\hline GO:0006968 & Cellular defense response & NCF1, TYROBP & $2.23 \times 10^{-2}$ & 18.6793053 \\
\hline GO:0005739 & Mitochondrion & $\begin{array}{l}\text { MRPS34, TIMM17A, NDUFS8, } \\
\text { CYC1, TIMM50 }\end{array}$ & $5.20 \times 10^{-5}$ & 0.044320277 \\
\hline GO:0005743 & $\begin{array}{l}\text { Mitochondrial inner } \\
\text { membrane }\end{array}$ & $\begin{array}{l}\text { TIMM17A, NDUFS8, CYC1, } \\
\text { TIMM50 }\end{array}$ & $5.34 \times 10^{-5}$ & 0.045471679 \\
\hline
\end{tabular}


Table II. Continued.

\begin{tabular}{|c|c|c|c|c|}
\hline ID & Name & Gene symbol & P-value & FDR \\
\hline GO:0019866 & Organelle inner membrane & $\begin{array}{l}\text { TIMM17A, NDUFS8, CYC1, } \\
\text { TIMM50 }\end{array}$ & $6.63 \times 10^{-5}$ & 0.056473574 \\
\hline
\end{tabular}

D, Cluster 4

\begin{tabular}{|c|c|c|c|c|}
\hline ID & Name & Gene symbol & P-value & FDR \\
\hline GO:0031966 & Mitochondrial membrane & $\begin{array}{l}\text { TIMM17A, NDUFS8, CYC1, } \\
\text { TIMM50 }\end{array}$ & $1.14 \times 10^{-4}$ & 0.096745997 \\
\hline GO:0005740 & Mitochondrial envelope & $\begin{array}{l}\text { TIMM17A, NDUFS8, CYC1, } \\
\text { TIMM50 }\end{array}$ & $1.37 \times 10^{-4}$ & 0.116223644 \\
\hline GO:0044429 & Mitochondrial part & $\begin{array}{l}\text { TIMM17A, NDUFS8, CYC1, } \\
\text { TIMM50 }\end{array}$ & $3.88 \times 10^{-4}$ & 0.329680741 \\
\hline GO:0031967 & Organelle envelope & $\begin{array}{l}\text { TIMM17A, NDUFS8, CYC1, } \\
\text { TIMM50 }\end{array}$ & $4.38 \times 10^{-4}$ & 0.372446101 \\
\hline GO:0031975 & Envelope & $\begin{array}{l}\text { TIMM17A, NDUFS8, } \\
\text { CYC1, TIMM50 }\end{array}$ & $4.42 \times 10^{-4}$ & 0.376016181 \\
\hline GO:0044455 & $\begin{array}{l}\text { Mitochondrial } \\
\text { membrane part }\end{array}$ & TIMM17A, NDUFS8, TIMM50 & $5.62 \times 10^{-4}$ & 0.47771995 \\
\hline GO:0031090 & Organelle membrane & $\begin{array}{l}\text { TIMM17A, NDUFS8, CYC1, } \\
\text { TIMM50 }\end{array}$ & $2.4 \times 10^{-3}$ & 1.987624717 \\
\hline GO:0005744 & $\begin{array}{l}\text { Mitochondrial inner } \\
\text { membrane presequence } \\
\text { translocase complex }\end{array}$ & TIMM17A, TIMM50 & $3.7 \times 10^{-3}$ & 3.15011107 \\
\hline GO:0070469 & Respiratory chain & NDUFS8, CYC1 & $2.3 \times 10^{-2}$ & 18.17151041 \\
\hline GO:0007005 & $\begin{array}{l}\text { Mitochondrion } \\
\text { organization }\end{array}$ & TIMM17A, NDUFS8, TIMM50 & $3.08 \times 10^{-4}$ & 0.286135591 \\
\hline GO:0022900 & Electron transport chain & NDUFS8, CYC1 & $2.5 \times 10^{-2}$ & 21.04388668 \\
\hline
\end{tabular}

GO, Gene ontology; FDR, false discovery rate.

risk factor for AAA, it is not surprising that olfactory receptor genes, including OR52E4, were enriched in cluster 1.

According to the result of GO function analysis cluster 2 was enriched in response to viruses and MX1, IFNAR and ISG20 were all included in cluster 2. Among these three DEGs, MX1 and IFNAR were observed to be upregulated, while ISG20 was downregulated. Previous studies have demonstrated that MX1, IFNAR and ISG20 are associated with the immune response to viruses (22-24). Accordingly, immune and inflammatory responses have been identified to be critical in AAA formation (25). These previous studies further confirm the role of the immune response in the pathogenesis of AAA.

$\mathrm{HCK}$ is an enzyme encoded by the HCK gene and is a member of the Src family of tyrosine kinases. HCK has been demonstrated to be involved in the migration and degranulation of neutrophils (26). TYROBP is an adaptor protein encoded by the TYROBP gene, which has been previously observed to be abnormally expressed in AAA (27). In agreement with this, the current study demonstrated that TYROBP and HCK were enriched in cluster 3 .

Various studies have established that oxidative stress may promote inflammation in the pathogenesis of AAA (28-30). In addition, mitochondrial-dependent apoptosis is reported to promote AAA formation in rodent experimental models (31). In accordance with this, the present study demonstrated that cluster 4 was enriched in mitochondria-associated functions and the oxidative phosphorylation subpathway. A variety of genes were enriched in cluster 4, including NDUFS8 and CYC1. NDUFS8 is encoded by the NDUFS8 gene and is a subunit of mitochondrial NADH (32). Consistently, NDUFS8 has been previously observed to be involved in oxidative phosphorylation (33). CYC1 is a heme protein encoded by the CYC1 gene, and cytochrome $c$ is a critical component of the electron transport chain in mitochondria (34). These studies are in agreement with the results of the current study, further suggesting the importance of mitochondria and oxidative phosphorylation in AAA. 
Table III. KEGG subpathway enrichment analysis for 4 clusters.

A, Cluster 1

\begin{tabular}{llll}
\hline ID & \multicolumn{1}{c}{ Name } & Gene symbol & P-value \\
\hline hsa04740 & Olfactory transduction & OR9A4, OR1L8, & $3.04 \times 10^{-5}$ \\
& & OR8B12, OR52E4, & \\
& OR4C46 &
\end{tabular}

B, Cluster 4

\begin{tabular}{|c|c|c|c|c|}
\hline ID & Name & Gene symbol & P-value & FDR \\
\hline hsa05012 & Parkinson's disease & NDUFS8, CYC1 & 0.025172075 & 10.49506004 \\
\hline hsa00190 & Oxidative phosphorylation & NDUFS8, CYC1 & 0.025565388 & 10.6520097 \\
\hline hsa05010 & Alzheimer's disease & NDUFS8, CYC1 & 0.032055064 & 13.21121831 \\
\hline hsa05016 & Huntington's disease & NDUFS8, CYC1 & 0.03539823 & 14.50736559 \\
\hline
\end{tabular}

KEGG, Kyoto Encyclopedia of Genes and Genomes; FDR, false discovery rate.

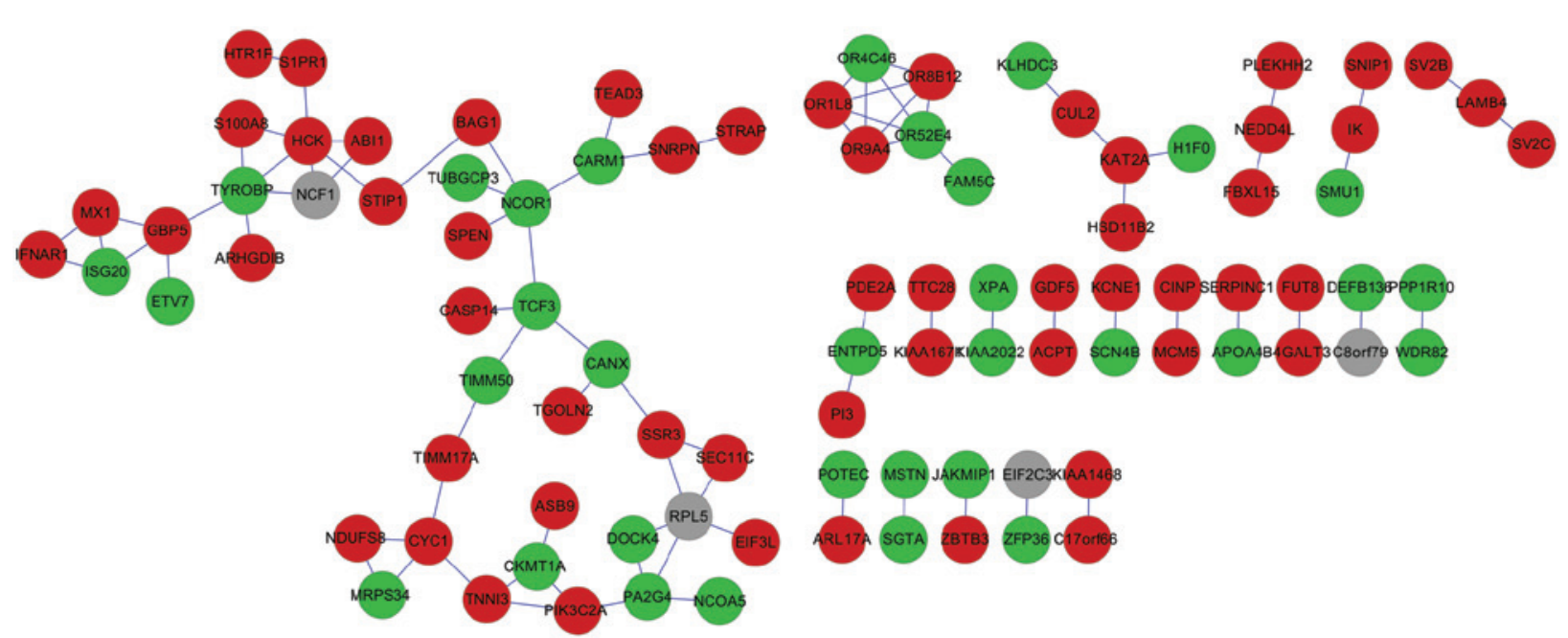

Figure 1. Protein-protein interaction network. Nodes, proteins; edges, interactions; red nodes, upregulated genes; green nodes, downregulated genes; gray nodes, genes whose expression remained unchanged between the abdominal aortic aneurysm samples and controls.

A

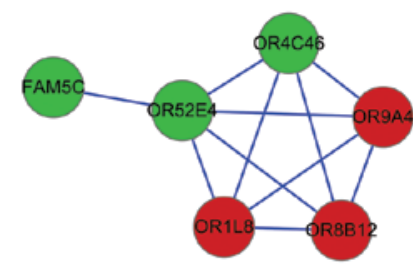

$\mathbf{C}$

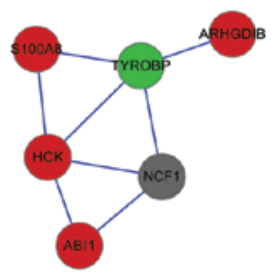

B

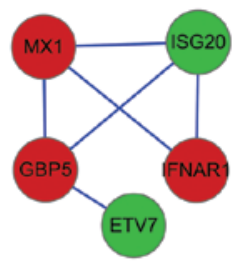

D

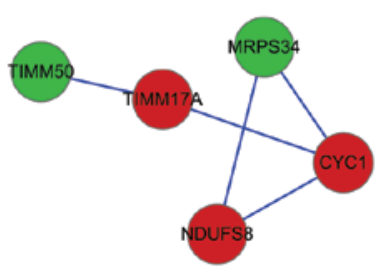

Figure 2. Four clusters from the protein-protein interaction network. Clusters (A) 1, (B) 2, (C) 3 and (D) 4. Nodes, proteins; edges, interactions; red nodes, upregulated genes; green nodes, downregulated genes; gray nodes, genes whose expression remained unchanged between the abdominal aortic aneurysm samples and controls. 
The current study demonstrated that EGR-1 and Myc were important TFs modulating upregulated DEGs, while ATF5 and SP1:SP3 were critical TFs for downregulated DEGs. EGR-1 has been identified to be an important TF and a tumor suppressor gene in addition (35). EGR-1 has been observed to be involved in thrombus formation and the inflammatory pathogenesis of AAA (36). The Myc protein is a member of the Myc family of transcription factors and has been demonstrated to be involved in regulating cell apoptosis and proliferation (37). The current study hypothesized that Myc may promote cell proliferation in AAA. In addition, $\mathrm{SP} 1$ is a protein encoded by the SP1 gene and belongs to the SP/Krüppel-like factor family of transcription factors (38). SP1 has been observed to modulate inflammation associated with AAA by increasing the expression levels of cyclooxygenase-2 (39). ATF5, encoded by ATF5 gene, belongs to the $\mathrm{ATF} / \mathrm{cyclic}$ adenosine monophosphate response-element binding (CREB) protein family (40). CREB has been reported to serve a role in modulating the apoptosis and proliferation of vascular smooth muscle cells $(41,42)$.

In conclusion, the current study indicated critical roles of the olfactory transduction, mitochondria and oxidative phosphorylation subpathways, and suggested the importance of the immune response in the pathogenesis of AAA. In addition, crucial TFs, including EGR-1, Myc, ATF5 and SP1:SP3, were identified and were suggested as potential treatment targets for this disease. Thus the present study aided in the further investigation of the pathogenesis of AAA. Further experimental studies are required in order to validate the results of the current study.

\section{References}

1. Schermerhorn M: A 66-year-old man with an abdominal aortic aneurysm: Review of screening and treatment. JAMA 302 2015-2022, 2009.

2. Upchurch GR Jr and Schaub TA: Abdominal aortic aneurysm Am Fam Physician 73: 1198-1204, 2006.

3. Shimazaki Y and Ueda H: Abdominal Aortic Aneurysm. In: Interdisciplinary Concepts in Cardiovascular Health Volume III: Cardiovascular events. Wakabayashi I and Groschne K (eds). Springer, Cham, Switzerland, pp161-179, 2014

4. Sode BF, Nordestgaard BG, Grønbæk M and Dahl M: Tobacco smoking and aortic aneurysm: Two population-based studies. Int J Cardiol 167: 2271-2277, 2013.

5. Kent KC, Zwolak RM, Egorova NN, Riles TS, Manganaro A, Moskowitz AJ, Gelijns AC and Greco G: Analysis of risk factors for abdominal aortic aneurysm in a cohort of more than 3 million individuals. J Vasc Surg 52: 539-548, 2010.

6. Kuivaniemi H, Shibamura H, Arthur C, et al: Familial abdominal aortic aneurysms: Collection of 233 multiplex families. J Vasc Surg 37: 340-345, 2003.

7. Defawe OD, Colige A,Lambert CA, et al: TIMP-2 and PAI-1 mRNA levels are lower in aneurysmal as compared to athero-occlusive abdominal aortas. Cardiovasc Res 60: 205-213, 2003.

8. Trivedi DB, Loftin CD, Clark J, Myers P, DeGraff LM, Cheng J, Zeldin DC and Langenbach R: $\beta$-Arrestin-2 deficiency attenuates abdominal aortic aneurysm formation in mice. Circ Res 112: $1219-1229,2013$

9. Jones GT, Bown MJ, Gretarsdottir S, et al: A sequence variant associated with sortilin-1 (SORT1) on 1p13.3 is independently associated with abdominal aortic aneurysm. Hum Mol Genet 22: 2941-2947, 2013.

10. Maegdefessel L, Azuma J, Toh R, et al: Inhibition of microRNA-29b reduces murine abdominal aortic aneurysm development. J Clin Invest 122: 497-506, 2012.

11. Bolstad BM: preprocessCore: A collection of pre-processing functions. R package, version 1.28.0, 2013. Available at: http:// bioconductor.org/packages/release/bioc/html/preprocessCore.html
12. Diboun I, Wernisch L, Orengo CA and Koltzenburg M: Microarray analysis after RNA amplification can detect pronounced differences in gene expression using limma. BMC Genomics 7: 252, 2006.

13. Gentleman RC, Carey VJ, Bates DM, et al: Bioconductor: Open software development for computational biology and bioinformatics. Genome Biol 5: R80, 2004.

14. Huang DW, Sherman BT, Tan Q, Collins JR, Alvord WG, Roayaei J, Stephens R, Baseler MW, Lane HC and Lempicki RA: The DAVID gene functional classification tool: A novel biological module-centric algorithm to functionally analyze large gene lists. Genome Biol 8: R183, 2007.

15. Ashburner M, Ball CA, Blake JA, et al; Gene ontology: Tool for the unification of biology. The Gene Ontology Consortium. Nat Genet 25: 25-29, 2000.

16. Arakawa K, Kono N, Yamada Y, Mori H and Tomita M: KEGG-based pathway visualization tool for complex omics data. In Silico Biol 5: 419-423, 2005.

17. Franceschini A, Szklarczyk D, Frankild S, et al: STRING v9.1: Protein-protein interaction networks, with increased coverage and integration. Nucleic Acids Res 41 (Database issue): D808-D815, 2013.

18. Shannon P, Markiel A, Ozier O, Baliga NS, Wang JT, Ramage D, Amin N, Schwikowski B and Ideker T: Cytoscape: A software environment for integrated models of biomolecular interaction networks. Genome Res 13: 2498-2504, 2003.

19. Nepusz T, Yu H and Paccanaro A: Detecting overlapping protein complexes in protein-protein interaction networks. Nat Methods 9: 471-472, 2012.

20. Malnic B, Godfrey PA and Buck LB: The human olfactory receptor gene family. Proc Natl Acad Sci USA 101: 2584-2589, 2004.

21. Katotomichelakis M, Balatsouras D, Tripsianis G, Davris S, Maroudias N, Danielides V and Simopoulos C: The effect of smoking on the olfactory function. Rhinology 45: 273-280, 2007.

22. Haller O, Staeheli P and Kochs G: Interferon-induced Mx proteins in antiviral host defense. Biochimie 89: 812-818, 2007.

23. Theofilopoulos AN, Baccala R, Beutler B and Kono DH: Type I interferons (alpha/beta) in immunity and autoimmunity. Annu Rev Immunol 23: 307-336, 2005.

24. Schoggins JW and Rice CM: Interferon-stimulated genes and their antiviral effector functions. Curr Opin Virol 1: 519-525, 2011.

25. Kwon YS and Kim DK: Pathogenesis of abdominal aortic aneurysm. J Korean Soc Vasc Surg 21: 78-83, 2005 (In Korean).

26. Stanglmaier M, Warmuth M, Kleinlein I, Reis S and Hallek M: The interaction of the Bcr-Abl tyrosine kinase with the Src kinase Hck is mediated by multiple binding domains. Leukemia 17 : 283-289, 2003

27. Lillvis JH, Kyo Y, Tromp G, et al: Analysis of positional candidate genes in the AAA1 susceptibility locus for abdominal aortic aneurysms on chromosome 19. BMC Med Genet 12: 14, 2011.

28. McCormick ML, Gavrila D and Weintraub NL: Role of oxidative stress in the pathogenesis of abdominal aortic aneurysms. Arterioscler Thromb Vasc Biol 27: 461-469, 2007.

29. Yajima N, Masuda M, Miyazaki M, Nakajima N, Chien S and Shyy JY: Oxidative stress is involved in the development of experimental abdominal aortic aneurysm: A study of the transcription profile with complementary DNA microarray. J Vasc Surg 36: 379-385, 2002

30. Kaneko H, Anzai T, Morisawa M, et al: Resveratrol prevents the development of abdominal aortic aneurysm through attenuation of inflammation, oxidative stress, and neovascularization. Atherosclerosis 217: 350-357, 2011

31. Sinha I, Sinha-Hikim AP, Hannawa KK, Henke PK, Eagleton MJ, Stanley JC and Upchurch GR Jr: Mitochondrial-dependent apoptosis in experimental rodent abdominal aortic aneurysms. Surgery 138: 806-811, 2005.

32. Procaccio V and Wallace DC: Late-onset Leigh syndrome in a patient with mitochondrial complex I NDUFS8 mutations. Neurology 62: 1899-1901, 2004.

33. Janssen RJ, van den Heuvel LP and Smeitink JA: Genetic defects in the oxidative phosphorylation (OXPHOS) system. Expert Rev Mol Diagn 4: 143-156, 2004.

34. Nord FF and Green DE: Electron transport and oxidative phosphorylation. Adv Enzymol Relat Areas Mol Biol 21: 73, 2006.

35. Gómez-Martín D, Díaz-Zamudio M, Galindo-Campos M and Alcocer-Varela J: Early growth response transcription factors and the modulation of immune response: Implications towards autoimmunity. Autoimmun Rev 9: 454-458, 2010. 
36. Shin IS, Kim JM, Kim KL, Jang SY, Jeon ES, Choi SH, Kim DK, Suh W and Kim YW: Early growth response factor-1 is associated with intraluminal thrombus formation in human abdominal aortic aneurysm. J Am Coll Cardiol 53: 792-799, 2009.

37. Pelengaris S, Rudolph B and Littlewood T: Action of Myc in vivo - proliferation and apoptosis. Curr Opin Genet Dev 10 $100-105,2000$

38. Safe S and Abdelrahim M: Sp transcription factor family and its role in cancer. Eur J Cancer 41: 2438-2448, 2005.

39. Xu Q, Ji YS and Schmedtje JF Jr: Sp1 increases expression of cyclooxygenase-2 in hypoxic vascular endothelium. Implications for the mechanisms of aortic aneurysm and heart failure. J Biol Chem 275: 24583-24589, 2000.
40. Vinson C, Myakishev M, Acharya A, Mir AA, Moll JR and Bonovich M: Classification of human B-ZIP proteins based on dimerization properties. Mol Cell Biol 22: 6321-6335, 2002.

41. Tokunou T, Shibata R, Kai H, et al: Apoptosis induced by inhibition of cyclic AMP response element-binding protein in vascular smooth muscle cells. Circulation 108: 1246-1252, 2003.

42. Ono H, Ichiki T, Fukuyama K, Iino N, Masuda S, Egashira K and Takeshita A: cAMP-response element-binding protein mediates tumor necrosis factor-alpha-induced vascular smooth muscle cell migration. Arterioscler Thromb Vasc Biol 24: 1634-1639, 2004. 